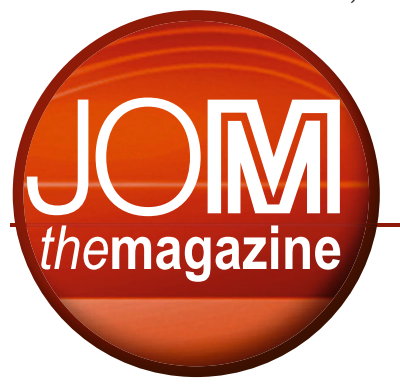

\title{
TMS content update
}

TMS2015 Proceedings Volumes Available for Preordering

Can't attend the

TMS 2015 Annual

Meeting \& Exhibition

(TMS2015), March

15-19, in Orlando,

Florida? You can still

access the papers

presented at TMS2015

by purchasing the

proceedings volumes

from the meeting,

available through

TMS's publishing

partner, John Wiley

\& Sons, at

www.wiley.com.

\section{6th International Symposium on High-Temperature \\ Metallurgical Processing}

Editors: Tao Jiang, Jiann-Yang Hwang, Gerardo R. F. Alvear F., Onuralp Yücel, Xinping Mao, Hong Yong Sohn, Naiyang Ma, Phillip J. Mackey, Thomas P. Battle

Highlights advancements in new high-temperature metallurgical technologies and their applications in such areas as: minerals processing, metals extraction, refractory and ceramic material preparation, fine particle sintering and synthesis, treatment and recycling of slags and wastes, energy efficiency, and environmental protection.

\section{Advanced Composites for Aerospace, Marine, and Land Applications II}

Editors: Tomoko Sano, T.S. Srivatsan

Offers valuable insights and understanding into the behavior of composite materials to guide selection and use for applications in aerospace, marine, and relevant land-based components and products.

\section{Advances in the Science and Engineering of Casting Solidification: An MPMD Symposium Honoring Doru Michael Stefanescu \\ Editors: Laurentiu Nastac, Baicheng Liu, Hasse Fredriksson, Jacques Lacaze, Chun-Pyo Hong, Adrian V. Catalina, Andreas Buhrig-Polaczek, Charles Monroe, Adrian S. Sabau, Roxana Elena Ligia Ruxanda, Alan Luo, Subhayu Sen, Attila Diószegi Explores the state-of-the-art in the science and engineering of casting solidification and the microstructure evolution of materials. This volume also introduces advanced characterization and multiscale modeling and simulation techniques, as well as related novel processing methods.}

\section{Characterization of Minerals, Metals, and Materials 2015}

Editors: John S. Carpenter, Chenguang Bai, J. Pablo Escobedo-Diaz, Jiann-Yang Hwang, Shadia J. Ikhmayies, Bowen Li, Jian Li, Sergio Neves Monteiro, Zhiwei Peng, Mingming Zhang Encompasses the full set of characterization techniques used across length scales-from macro to atomic scale-and examines topics ranging from structural steels to electronic materials to plantbased composites.

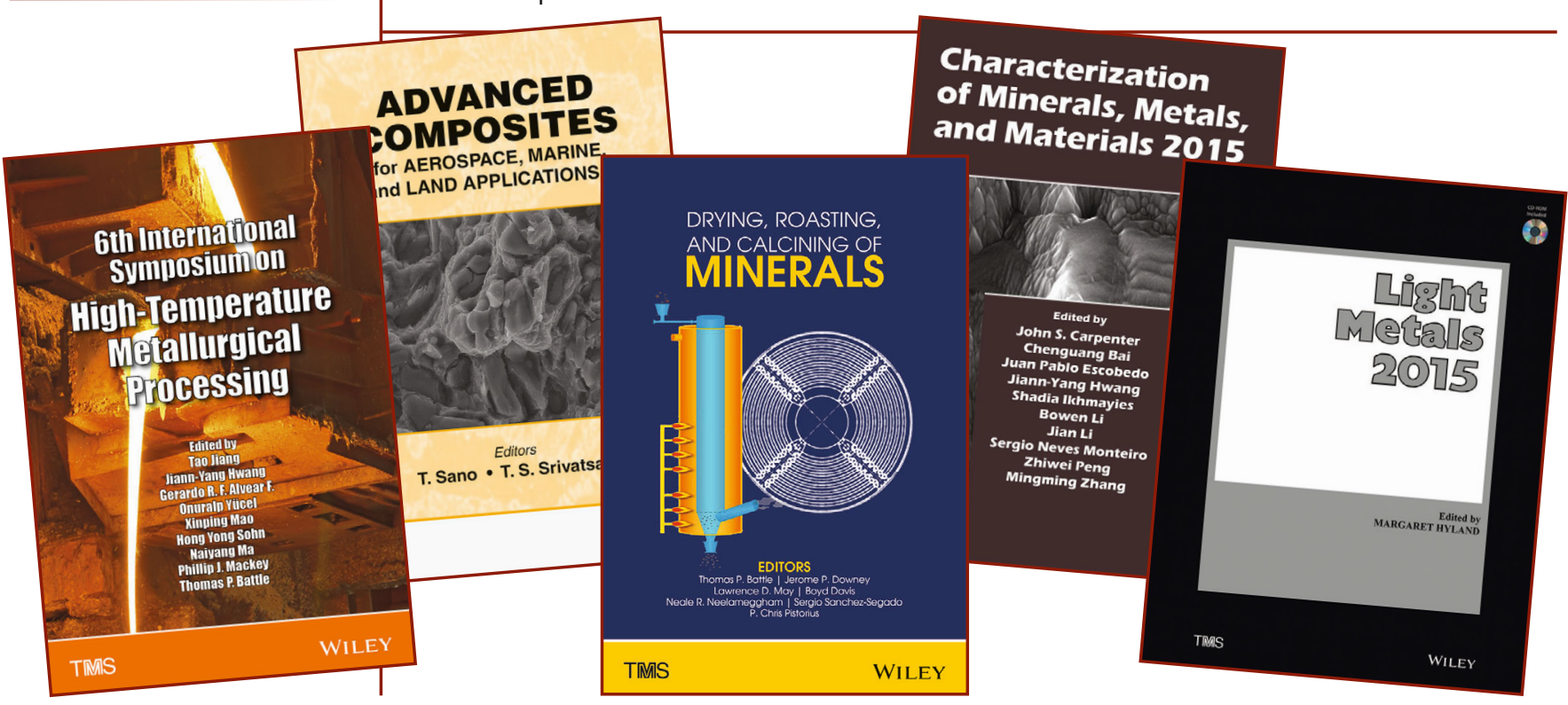




\section{Drying, Roasting, and Calcining of Minerals}

Editors: Thomas P. Battle, Jerome P. Downey, Lawrence D. May, Boyd Davis,

Neale R. Neelameggham, Sergio Sanchez-Segado, P. Chris Pistorius

Provides focused information on important extractive metallurgy unit operations that are generally presented as ancillaries to the core unit operations and rarely discussed in their own proceedings volume.

\section{Energy Technology 2015: Carbon Dioxide Management and Other Technologies}

Editors: Animesh Jha, Cong Wang, Neale R. Neelameggham, Donna P. Guillen, Li Li,

Cynthia K. Belt, Randolph Kirchain, Jeffrey Spangenberger, Frank Johnson,

Andrew Jewel Gomes, Amit Pandey, Peter Hosemann

Showcases the technological aspects of sustainable energy ecosystems and processes that improve energy efficiency, and reduce and sequestrate carbon dioxide and other greenhouse emissions. In particular, the volume highlights innovations in energy efficiency focused on ore beneficiation, smelting, recycling, and waste heat recovery. Papers from multiple TMS2015 energy-related symposia are included in this volume.

\section{EPD Congress 2015}

Editors: James Yurko, Antoine Allanore, Laura Bartlett, Jonghyun Lee, Lifeng Zhang, Gabriella Tranell, Yulia Meteleva-Fischer, Shadia Ikhmayies, Arief Budiman, Prabhat Tripathy, Guy Fredrickson

Compiles papers from one of the largest yearly gatherings of extraction specialists in the world, covering many aspects of extraction and processing metallurgy.

\section{Friction Stir Welding and Processing VIII}

Editors: Rajiv S. Mishra, Murray W. Mahoney, Yutaka Sato, Yuri Hovanski

Covers the fundamentals and current status of friction stir welding and solid-state friction stir processing of materials.

\section{Light Metals 2015}

Editor: Margaret Hyland

Spotlights new research within the following topic areas: Alumina and Bauxite; Aluminum Alloys: Fabrication, Characterization and Applications; Aluminum Processing; Aluminum Reduction Technology; Cast Shop for Aluminum Production; Electrode Technology for Aluminum Production; and Strip Casting of Light Metals. For more than 40 years Light Metals has been one of the most widely recognized and authoritative sources of information on new developments in aluminum production technology.

\section{Magnesium Technology 2015}

Editors: Michele V. Manuel, Alok Singh, Martyn L. Alderman, Neale R. Neelameggham Explores a broad range of current topics, including alloys and their properties; cast products and processing; wrought products and processing; forming, joining, and machining; corrosion and surface finishing; ecology; and structural applications. Also covers new and emerging applications.

\section{Rare Metal Technology 2015}

Editors: Neale R. Neelameggham, Shafiq Alam, Harald Oosterhof, Animesh Jha, Shijie Wang, David Dreisinger

Focuses on new research and advancements in the extraction of rare metals, as well as processing techniques such as bio-leaching, molecular recognition technology, and recovery of valuable components of commodity metals. This volume has been developed for use throughout commodity metal production, irrespective of major metal, by highlighting cross-application among industries.

\section{TMS2015 Supplemental Proceedings}

Presents papers from the TMS 2015 Annual Meeting \& Exhibition, encompassing a wide range of topics of value to the minerals, metals, and materials communities, from basic research to industrial application.
TMS members

receive a 35 percent

discount on the

list price of these

publications, as well

as other products

sold by Wiley. Access

the member discount

code in the TMS-

Wiley Bookstore

section of the TMS

Knowledge Resource

Center at

knowledge.tms.org. 